\title{
Literature Review on Disruption Recovery in the Supply Chain
}

\section{DMITRY IVANOV,${ }^{* 4}$ ALEXANDRE DOLGUI, ${ }^{1}$ BORIS SOKOLOV,${ }^{2,3}$ MARINA IVANOVA ${ }^{4}$}

\author{
${ }^{1}$ Automation, Production and Computer Sciences Dept. \\ IMT Atlantique (former Ecole des Mines de Nantes) \\ LS2N - CNRS UMR 6004 La Chantrerie \\ 4, rue Alfred Kastler - B.P. 20722 ; F-44307 NANTES Cedex 3, France \\ Alexandre.dolgui@imt-atlantique.fr \\ ${ }^{2}$ St. Petersburg Institute for Informatics and Automation of the RAS (SPIIRAS) \\ V.O. 14 line, 39199178 St. Petersburg, Russia; email: sokol@iias.spb.su \\ ${ }^{3}$ Saint Petersburg National Research University of Information Technologies, Mechanics and Optics (ITMO), \\ Russia \\ ${ }^{4}$ Berlin School of Economics and Law, Department of Business and Economics \\ 10825 Berlin, Germany; Phone: +49 3085789155; email: divanov@hwr-berlin.de
}

\author{
*Corresponding author \\ Prof. Dr Dmitry Ivanov \\ Berlin School of Economics and Law, Department of Business and Economics \\ Professor of Supply Chain Management, \\ 10825 Berlin, Germany \\ Phone: +49 3085789155; \\ email: divanov@hwr-berlin.de
}

\begin{abstract}
Recent research underlines the crucial role of disruption events and recovery policies in supply chains. Despite a wealth of literature on supply chain design with disruption considerations, to the best of our knowledge there is no survey on supply chain with disruptions and recovery considerations. We analyse state-of-the-art research streams on supply chain design and planning with both disruptions and recovery considerations with the aim of relating the existing quantitative methods to empirical research. The paper structures and classifies existing research streams and application areas of different quantitative methods subject to different disruption risks and recovery measures. We identify gaps in current research and delineate future research avenues. The results of this study are twofold: operations and supply chain managers can observe which quantitative tools are available for different application areas; on other hand, limitations and future research needs for decision-support methods in supply chain risk management domains can be identified.
\end{abstract}

Keywords: supply chain dynamics; supply chain risk management; supply chain resilience; supply chain design; supply chain engineering 
D. Ivanov, A. Dolgui, B. Sokolov, M. Ivanova. Literature review on disruption recovery in the supply chain

This is an extended version of the conference paper:

Ivanov, D., Dolgui, A., Sokolov, B., Ivanova M. (2016). Disruptions in supply chains and recovery policies: state-of-the art review. IFAC-PapersOnLine 49(12), 8th IFAC Conference on Manufacturing Modelling, Management and Control (MIM 2016), Edited by Alexandre Dolgui, Robert Grubbström, Dmitry Ivanov and Farouk Yalaoui, pp. 1436-1441.

\section{INTRODUCTION}

SCD (supply chain design) considers facility location planning, allocation of customers to distribution centers or factories, and supplier selection (Melo et al. 2009; Chopra and Meindl 2012; Sawik 2013, Nair et al. 2015, Martel and Klibi 2016, Ivanov et al. 2017). Quantitative analysis methods help to compute optimal SCD structures on the basis of several assumptions and constraints regarding demand, supply and transportation capacities (Sourirajan et al. 2009; Sadjady and Davoudpour 2012; Singh et al. 2012; Kumar and Tiwari 2013; Pan and Nagi 2013; Askin et al. 2014). The objectives are related to costs minimization subject to some service level requirements. The results of the SCD influence supply chain planning (SCP) decisions. Examples of SCP decisions comprise inventory management, distribution and transportation planning (Manzini and Bindi 2009; Ravindran et al. 2010; Constantino et al. 2012; Bowersox et al. 2013; Ivanov et al. 2014b).

Uncertainty and risks play crucial role in both SCD and SCP decisions. Recurrent or operational risks and disruptive risks (Tang 2006, Chopra et al. 2007, Tsai 2016, Rezapour et al. 2017, Ivanov 2017a) are typically involved with those considerations. Demand and lead-time uncertainty risks are related to operational risks (Kleindorfer and Saad 2005; Chopra et al. 2007; Acar et al. 2010; Georgiadis et al. 2011; Hora and Klassen 2013; Meisel and Bierwirth 2014) and are frequently considered in the framework of bullwhip-effect (Dejonckheere et al. 2003, Ouyang and Li 2010). SC managers achieved significant improvements at managing the SCs and mitigating recurrent $\mathrm{SC}$ risks through improved coordinated planning and execution, e.g., vendor-managed inventory (VMI) or collaborative planning, forecasting and replenishment (CPFR) (Chopra and Sodhi 2014; Govindan 2015; Xu et al. 2015).

Disruption risks result from natural and man-made disasters, strikes, severe legal disputes, etc (Chopra and Sodhi 2014; Simchi-Levi et al. 2014). Knemeyer et al. (2009), Hora and Klassen (2013) and Ambulkar et al. (2015) underline that recovery policies in supply chains (SC) are crucial to cope with disruption events. The studies by Ivanov et al. (2014a,b), Sokolov et al. (2016), Ivanvo et al. (2017) and Ivanov (2017) clearly distinguish bullwhip effect and the ripple effect that may arise in case of disruptive risks subject to structural disruptions in the SC. The ripple effect describes the impact of a disruption on SC performance and the disruption-based scope of changes in the SC structures. Managing the ripple effect is closely related to a proactive design and planning of robust and resilient SCs and creating recovery policies.

Recent studies extensively considered proactive stage of SCD and SCP taking into account disruption risks (e.g. Xia et al. 2004; Snyder and Daskin 2005; Xiao and Yu 2006; Wilson 2007; Cui et al. 2010; Baron et al. 2011; Chen et al. 2011; Peng et al. 2011; Kouvelis and Li 2012; Schmitt and Singh 2012; Sodhi et al. 2012; Chen and Miller-hooks 2012, Baghalian et al. 2013; Ivanov et al. 2013; 2014a; Li et al. 2013; Lim et al. 2013; Qi 2013; Sawik 2013; Paul et al. 2014, Kamalahmadi and Parast 2016). A number of remarkable state-of-the-art reviews 
D. Ivanov, A. Dolgui, B. Sokolov, M. Ivanova. Literature review on disruption recovery in the supply chain

and conceptual frameworks have been published in this area (Klibi et al. 2010; Lim et al. 2010; Blackhurst et al. 2011; Christopher et al. 2011; Klibi and Martel 2012; Simangunsong et al. 2012; Pettit et al. 2013; Tang et al. 2014; Ambulkar et al. 2015).

It can be observed in the existing studies that two groups of problem statements are generally considered (see Figure 1):

- disruption consideration without recovery measures

- disruption consideration with recovery measures.



Figure 1. Disruption consideration with and without recovery measures

Despite a wealth of literature and state-of-the-art surveys on proactive SCD and SCP with disruption considerations, to the best of our knowledge there is no state-of-the art review on SCD and SCP with disruptions and recovery considerations. The goal of this study is to structure and classify existing research streams and application areas of different methods for SCD and SCP with disruptions and recovery considerations as well as identifying gaps in current research and delineating future research avenues with the aim of relating the existing quantitative methods to empirical research.

This paper is based on the conference paper (Ivanov et al. 2016c). We extend the conference paper in regard to the scope of reviewed papers and analysis of current and future research streams. The remainder of this paper is organized as follows. Section 2 provides a state-of-the-art overview of research on disruption risks with recovery considerations in SCD and SCP with the help of quantitative methods. In Section 3, analysis of the considered literature is performed regarding the reasons for different risks, proactive and reactive measures for risk mitigation and recovery, and application areas of different quantitative methods. Section 4 identifies gaps in current research and delineates future research needs. The paper concludes by summarizing the most important insights from the research.

\section{STATE-OF-THE-ART OVERVIEW}

\subsection{Literature selection}

In the last decade, reasons for disruptions in SCs have been extensively investigated. Numerous studies including (but not limited to) the works of Hendricks and Singhal (2005); Kleindorfer and Saad (2005); Tomlin (2006); Craighead et al. (2007); Blackhurst et al. (2011); Bode et al. (2011); Nair and Vidal (2011), Simangunsong et al. (2012), Pettit et al. (2013); Tang et al. (2014); Ivanov et al. (2014a,b), Ambulklar et al. (2015), Ho et al. (2015), Gunasekaran et al. (2015), Tukamuhabwa et al. (2015), Gupta et al. (2016), Ivanov et al.(2016a,b), Ivanov 
D. Ivanov, A. Dolgui, B. Sokolov, M. Ivanova. Literature review on disruption recovery in the supply chain

(2017), Khalili et al. (2017), Yu et al. (2017) revealed basic reasons for the disruptions and their impact on SC execution and performance.

In order to restrict ourselves to quantitative methods, we feel that a review of the wealth of literature on SC risk management and collaboration strategies is out of scope of this paper. We refer to the works of Hallikas et al. (2004); Zsidisin et al. (2004); Hendricks and Singhal (2005); Kleindorfer and Saad (2005); Tomlin (2006); Craighead et al. (2007); Ritchie and Brindley (2007); Blackhurst et al. (2011); Bode et al. (2011); Chaudhuri et al. (2013); Chen et al. (2013); Pettit et al. (2013); Ambulkar et al. (2015) for the state-of-the-art research on SC risk management and collaborative approaches to recovery deployment.

In quantitative analysis, two basic approaches to hedging the SC against negative impacts of different disruptions - proactive and reactive - have been developed in recent years. The proactive approach creates certain protections and takes into account possible perturbations without recovery considerations while generating SCD (Klibi et al. 2010, Snyder et al. 2016). The reactive approach aims at adjusting SC processes and structures in the presence of unexpected events (Knemeyer et al. 2009, Ivanov et al. 2016a,b).

Literature on proactive strategies to SC disruption management suggests different approaches to generate robust and resilient SC structures. Studies by Snyder and Daskin (2005); Goh et al. (2007); Wilson (2007); Wu et al. (2007); Cui et al. (2010); Ravindran et al. 2010; Peng et al. (2011); Yang et al. (2012); Ahmadi-Javid and Seddighi (2013); Baghalian et al. (2013); Benyoucef et al. (2013); Xu et al. (2014), Sawik (2016), Spiegler et al.(2016), Mizgier (2017), Lin et al. (2017) belong to the recommendable references on proactive approach.

The literature selection for this study has been made on the basis of the following principles. The first principle is the objectives of this study. To these objectives belong:

- identifying reasons for risks in SCs in both qualitative and quantitative literature

- identifying measures for SC recovery in both qualitative and quantitative literature

- bridging reasons and recovery measures for development of contingency plans

- deriving commonalities/differences in qualitative and quantitative research on SC risks

- analysing different methods for quantitative analysis of SCD and SCP.

The second principle was to present a state-of-the-art review on a broad, multidisciplinary basis. This implies consideration of different research methodologies such as optimization, simulation, and control theory. The third principle was to cover two groups of problem statements:

- risk consideration without recovery measures

- risk consideration with recovery measures.

We emphasize that this analysis does not pretend to be a full collection of the papers published on the selected topic but rather aims at bridging scientific results and managerial needs in order to provide SC managers with an overview of current research trends in the area.

\subsection{Mixed-integer programming}

Mixed-integer programming (MIP) has been extensively applied to SCD beginning with the seminal study by Snyder and Daskin (2005). The model aims at finding optimal SCD with assignments of customers to locations with the objective to minimize total SC costs. Lim et al. (2010) applied MIP model to incorporate a totally reliable backup supplier which can be used if a primary supplier is destroyed. The related recovery costs are incor- 
D. Ivanov, A. Dolgui, B. Sokolov, M. Ivanova. Literature review on disruption recovery in the supply chain

porated into the objective function. Li et al. (2013) extended this model by introducing limits to the fortification budget.

Chen et al. (2011) developed a joint inventory-location model under the risk of stochastic facility disruptions. Another approach is taken by Lim et al. (2013). The authors turned away from probability estimation issues and faced the trade-off of under- vs over-estimation of disruption probabilities. The results suggest that an underestimation of disruptions may have significantly higher impacts on the total SC costs as compared to overestimation. Such analysis has been performed on the basis of a stylized continuous location model.

Rafiei et al. (2013) developed a comprehensive model for a problem statement with multiple products and many periods with considerations of inventory, back ordering, available machine capacity and labour levels for each source, transportation capacity at each trans-shipment node and available warehouse space at each destination. The authors analyse the settings with a backup supplier with reserved capacity and a backup trans-shipment node that satisfied demands at higher prices without disruption facility. The solution to the model is based on a priority-based genetic algorithm.

Hasani and Khosrojerdi (2016) used an MIP model to investigate resilience in light of correlated disruptions. Solution is implemented as a Taguchi-based memetic algorithm that incorporates a customized hybrid parallel adaptive large neighborhood search. The model is solved for a real-life case of a global medical device manufacturer.

Rezapour et al. (2017) developed a resilient topology of an SC that is able to recover from and react quickly to disruptions. Three policies are analysed in regard to keeping emergency stock at the retailers, reserving back-up capacity at the suppliers, and multiple-sourcing. The authors apply non-linear MIP model to find the most profitable network and mitigation policies. Major results of this study suggest that risk mitigation policies not only improve the SC control by sustaining and improving its market share but also benefit customers by stabilizing retail prices in the market. Further, the analysis reveals that downstream "emergency stock" is the most preferable risk mitigation strategy if suppliers are unreliable.

\subsection{Stochastic programming}

Objective functions in stochastic programming approaches contain the sum of the first-stage performance measure and the expected second-stage performance. Stochastic programming models are scenario-based and parameters are represented by a set of discrete scenarios with a given probability of occurrence.

Typically, in classical stochastic programming models (Tsiakis et al. 2001; Santoso et al. 2005; Goh et al. 2007), demand is considered as an uncertain parameter. In robust stochastic programming models (Azaron et al. 2008), facility disruptions and capacity expansion costs are also considered to be uncertain. Sawik (2013) developed a stochastic programming model for integrated supplier selection, order quantity allocation and customer order scheduling in the presence of SC disruption risks. Torabi et al. (2015) develop a bi-objective mixed two-stage stochastic programming model for supplier selection and order allocation problem under operational and disruption risks. The model considers several reactive strategies such as suppliers' business continuity plans and using backup suppliers. 
D. Ivanov, A. Dolgui, B. Sokolov, M. Ivanova. Literature review on disruption recovery in the supply chain

\subsection{Inventory management and contracting}

Federgruen and Yang (2011) presented a general periodic review model to analyse the dynamic effects of inventory buffers in the case of unreliable suppliers. Qi (2013) developed a continuous review inventory model with random disruptions at the primary supplier. Hishamuddin et al. (2013) presented a recovery model for a twoechelon serial SC with consideration of transportation disruption. Their model is capable of determining the optimal ordering and production quantities during the recovery period to minimize total costs

Hou et al. (2010) analyse the coordination with a backup supplier through a buy-back contract under supply disruption. Iakovou et al. (2010) analyse a single period stochastic inventory model for capturing the trade-off between inventory policies and disruption risks for an unreliable dual sourcing supply network for both the capacitated and incapacitated cases. They evaluate the merit of different contingency strategies. Shao and Dong (2012) analyse an assemble-to-order system with a backup source to offer on-time delivery and a compensation policy to compensate customers for waiting in each period during the disruption. The findings suggest that the backup sourcing strategy is preferred at the beginning of the supply disruption, while the compensation strategy is preferred as time elapses. For the considered example, the dynamic mixed strategy with customer choices is superior to the pure backup sourcing strategy. The backup cost and customer sensitivity are two determining factors in the manufacturer's choice of the reactive strategies.

$\mathrm{Hu}$ et al. (2013) analyse the incentive mechanisms to motivate a supplier's investment in capacity restoration. They consider cases where the incentive is committed to ex ante (prior to disruption) and when it is committed to ex post (after disruption). The analysis indicates if the buyer offers incentives, both the buyer and the supplier (weakly) prefer the ex ante commitment over the ex post one. The study by Kim and Tomlin (2013) indicates that if recovery capacity investment is the only option, the firms in a decentralized setting overinvest in capacity, resulting in higher system availability but at a higher cost. If both investments can be made, the firms typically underinvest in failure prevention and overinvest in recovery capacity.

Lewis et al. (2013) analyse the disruption risks at ports of entry with the help of closure likelihood and duration which are modelled using a completely observed, exogenous Markov chain. They developed a periodic review inventory control model that indicates for studied scenarios that operating margins may decrease $10 \%$ for reasonably long port-of-entry closures or be eliminated completely without contingency plans, and that expected holding and penalty costs may increase $20 \%$ for anticipated increases in port-of-entry utilization.

Gupta et al. (2015) study from game-theoretical perspective the implications of the contingent sourcing strategy under competition and in the presence of a possible supply disruption. The time of the occurrence of the supply disruption is uncertain and exogenous, but the procurement time of components is in the control of the firms. The results imply that supply disruption and procurement times jointly impact the firms' buying decisions, optimal order quantities and their expected profits. Subsequently, this study considers the impact endogenizing equilibrium sourcing strategies of asymmetric and symmetric firms, and of capacity reservation to mitigate disruption.

\subsection{Simulation, system science and control theory}

Simulation approaches have been proved to be a suitable tool for analysis of SCD in terms of the ripple effect. Schmitt and Singh (2012) presented a quantitative estimation of the disruption risk at production and supply 
capacities in a multi-echelon SC using discrete-event simulation. They also consider dual sourcing as a contingency measure. The disruption risk is measured by "weeks of recovery" as the amplification of the disruption. Carvalho et al. (2012) analysed impacts of transportation disruptions on lead-time and overall costs in an automotive SC using an ARENA-based simulation model.

Unnikrishnan and Figliozzi (2011) developed a scenario-based model with an adaptive routing policy. Vahdani et al. (2011) applied fuzzy programme evaluation and a review technique to calculate the completion time of SC operations in the case of severe disruption. Xu et al. (2014) used AnyLogic software and modelled SC as an agent system to study the disruption at suppliers and recovery policies of the SC service level.

Ivanov et al. (2013) included transportation reconfiguration in the case of SC disruptions into the SCD in a multi-period model based on a combination of linear programming (LP) and optimal control. Ivanov et al. (2014a) present a hybrid control-theoretic approach on the basis of optimal and feedback control to cope with the ripple effect in the SC. Ivanov et al. (2014b) developed a model for multi-period and multi-commodity SCD with structure dynamics considerations. The original idea of these studies is SC description as a non-stationary dynamic control system along with an LP model. They distribute static and dynamic parameters between the LP and control models.

$\mathrm{Xu}$ et al. (2014) developed an approach to predict SC resilience by including recovery measures that use the analogy to biological cells with the ability for self-adaptation and self-recovery. Paul et al. (2014) analysed series of disruptions over time and presented an inventory control-based model to develop optimal recovery policies for real-time disruption management for a two-stage batch production-inventory system with reliability considerations. They consider multiple disruptions and cases where new disruption may or may not affect the recovery plan of earlier disruptions. Ivanov et al. (2016a) studied disruption-driven SC (re)-planning and performance impact assessment with consideration of proactive and recovery policies. Ivanov et al. (2016b) applied simulation to the analysis of dynamic recovery policies for time-critical SCs under conditions of ripple effect.

Raj et al. (2014) develop a survival model to represent a time period from the time the system failed to function to the time the system returns with its function (i.e., recovery). The input to the model is a failure event; the output of the model is the recovery time. The model allows a quantitative measurement of SC resilience in terms of recovery time.

Spiegler et al. (2015, 2016), Spiegler and Naim (2017) demonstrate that inclusion of non-linear dynamics nonlinearities can yield unexpected dynamic behaviours in a production and inventory control system, such as sustained oscillations or limit cycles. It can be helpful in order to avoid simulating complex models without preliminary analysis and to recognise the non-linearity effects. For example, Spiegler et al. (2016) apply nonlinear control theory in investigating the underlying dynamics and resilience of a grocery SC

\section{ANALYIS AND OBSERVATIONS}

\subsection{Literature analysis}

Based on the multidisciplinary literature analysis, our next objective is to derive some classifications regarding the following issues:

- what types of disruptive risks should be considered by SC managers

- how to protect the SC against disruptions 
D. Ivanov, A. Dolgui, B. Sokolov, M. Ivanova. Literature review on disruption recovery in the supply chain

- how to react in the case of disruptions

- which methods are mostly suitable for certain problems in SC risk management and control.

Table 1 depicts the matrix 'risks-recovery'. In Table 2, the matrix 'methods-contingency plans' is presented.

Table 1. Matrix 'risks-recovery'

\begin{tabular}{|c|c|c|c|}
\hline & Inventory & Capacity & $\begin{array}{l}\text { Dual/multiple vendors } \\
\text { Backup suppliers }\end{array}$ \\
\hline $\begin{array}{l}\text { Production } \\
\text { disruptions }\end{array}$ & $\begin{array}{l}\text { Vahdani et al. (2011), } \\
\text { Rafiei et al. (2013), } \\
\text { Paul et al. (2014), Iva- } \\
\text { nov et al. (2016a,b), } \\
\text { Ivanov (2017), } \\
\text { Rezapour et al. (2017), } \\
\text { Spiegler et al. (2017) }\end{array}$ & $\begin{array}{l}\text { Azaron et al. (2008), } \\
\text { Ivanov et al. (2013, } \\
2014 b) \text { Torabi et al. } \\
(2015) \text {, Rezapour et al. } \\
(2017)\end{array}$ & $\begin{array}{l}\text { Lim et al. (2010), Schmitt and Singh } \\
\text { (2012), Li et al. (2013), Ivanov et al. } \\
\text { (2013, 2014b), Sawik (2016), Iva- } \\
\text { nov et al. (2016a,b), Ivanov (2017), } \\
\text { Rezapour et al. (2017) }\end{array}$ \\
\hline $\begin{array}{l}\text { Supply disrup- } \\
\text { tions }\end{array}$ & $\begin{array}{l}\text { Vahdani et al. (2011), } \\
\text { Hu et al. (2013), Iako- } \\
\text { vou et al. (2010), Shao } \\
\text { and Dong (2012), Paul } \\
\text { et al. (2014), Hasani, } \\
\text { and Khosrojerdi (2016) }\end{array}$ & $\begin{array}{l}\text { Azaron et al. (2008), } \\
\text { Ivanov et al. (2013, } \\
2014 \mathrm{~b}), \text { Kim and Tomlin } \\
(2013), \text { Ivanov et al. } \\
(2016 \mathrm{a}, \mathrm{b}), \quad \text { Ivanov } \\
(2017), \text { Rezapour et al. } \\
(2017)\end{array}$ & $\begin{array}{l}\text { Hou et al. (2010), Lim et al. (2010), } \\
\text { Yang et al. (2012), Sawik (2013), } \\
\text { Schmitt and Singh (2012), Shao and } \\
\text { Dong (2012), Ivanov et al. (2013, } \\
\text { 2014b), Li et al. (2013), Gupta and } \\
\text { Sethi (2015), Ivanov et al. } \\
\text { (2016a,b), Ivanov (2017), Rezapour } \\
\text { et al. (2017) }\end{array}$ \\
\hline $\begin{array}{l}\text { Transportation } \\
\text { disruptions }\end{array}$ & $\begin{array}{l}\text { Carvalho et al. (2012), } \\
\text { Hishamuddin et al. } \\
\text { (2013), Lewis et al. } \\
(2013) \text {, Paul et al. } \\
(2014)\end{array}$ & $\begin{array}{l}\text { Azaron et al. (2008), } \\
\text { Ivanov et al. (2013, } \\
2014 b) \text { Lewis et al. } \\
(2013) \text { Gedik et al. } \\
(2014) \text { Hasani, and } \\
\text { Khosrojerdi (2016) }\end{array}$ & $\begin{array}{l}\text { Unnikrishnan and Figliozzi (2011), } \\
\text { Ivanov et al. (2013, 2014b), Lewis } \\
\text { et al. (2013) }\end{array}$ \\
\hline
\end{tabular}


D. Ivanov, A. Dolgui, B. Sokolov, M. Ivanova. Literature review on disruption recovery in the supply chain

Table 2. Matrix 'methods-contingency plans'

\begin{tabular}{|c|c|c|c|c|c|}
\hline & & $\begin{array}{l}\text { Mixed-integer } \\
\text { programming }\end{array}$ & $\begin{array}{l}\text { Stochastic pro- } \\
\text { gramming }\end{array}$ & $\begin{array}{l}\text { Simulation and control } \\
\text { theory }\end{array}$ & $\begin{array}{l}\text { Inventory management } \\
\text { and contracting }\end{array}$ \\
\hline$\frac{\mathscr{y}}{\underline{a}}$ & $\begin{array}{l}\text { Production dis- } \\
\text { ruptions }\end{array}$ & $\begin{array}{l}\text { Lim et al. } \\
(2010), \text { Li et al. } \\
(2013) \\
\text { Rezapour et al. } \\
(2017)\end{array}$ & $\begin{array}{l}\text { Azaron et al. } \\
\text { (2008), Torabi } \\
\text { et al. (2015) }\end{array}$ & $\begin{array}{l}\text { Paul et al. (2014), Schmitt } \\
\text { and Singh (2012), Vahda- } \\
\text { ni et al. (2011), Ivanov et } \\
\text { al. (2013, 2014a), Ivanov } \\
\text { et al. (2016a,b), Ivanov } \\
\text { (2017), Spiegler et al. } \\
\text { (2017) }\end{array}$ & \\
\hline : & $\begin{array}{l}\text { Supply disrup- } \\
\text { tions }\end{array}$ & $\begin{array}{l}\text { Lim et al. } \\
(2010), \text { Hasani, } \\
\text { and Khosrojerdi } \\
(2016)\end{array}$ & $\begin{array}{l}\text { Azaron et al. } \\
\text { (2008), Sawik } \\
(2013,2016) .\end{array}$ & $\begin{array}{l}\text { Carvalho et al. (2012), } \\
\text { Vahdani et al. (2011), } \\
\text { Ivanov et al. (2013, } \\
\text { 2014b) }\end{array}$ & $\begin{array}{l}\text { Hishamuddin et al. } \\
\text { (2013), Gupta and Sethi } \\
\text { (2015) }\end{array}$ \\
\hline & $\begin{array}{l}\text { Transportation } \\
\text { disruptions }\end{array}$ & & $\begin{array}{l}\text { Azaron et al. } \\
(2008)\end{array}$ & $\begin{array}{l}\text { Schmitt and Singh (2012), } \\
\text { Vahdani et al. (2011), } \\
\text { Ivanov et al. (2013, } \\
\text { 2014b), Ivanov et al. } \\
\text { (2016a,b) }\end{array}$ & $\begin{array}{l}\text { Hou et al. (2010), Hu et } \\
\text { al. (2013), Iakovou et al. } \\
\text { (2010), Shao and Dong } \\
\text { (2012), Lewis et al. } \\
\text { (2013) }\end{array}$ \\
\hline$\stackrel{\dot{d}}{\rightleftarrows}$ & $\begin{array}{l}\text { Alternative sup- } \\
\text { pliers }\end{array}$ & & & $\begin{array}{l}\text { Schmitt and Singh (2012), } \\
\text { Ivanov et al. (2013, } \\
2014 b)\end{array}$ & $\begin{array}{l}\text { Iakovou et al. (2010), } \\
\text { Lewis et al. (2013) }\end{array}$ \\
\hline 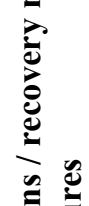 & Inventory & $\begin{array}{l}\text { Paul et al. } \\
(2014) \\
\text { Rezapour et al. } \\
(2017)\end{array}$ & & $\begin{array}{l}\text { Carvalho et al. (2012), } \\
\text { Schmitt and Singh (2012), } \\
\text { Vahdani et al. (2011), } \\
\text { Ivanov et al. (2016a,b), } \\
\text { Ivanov (2017) }\end{array}$ & $\begin{array}{l}\text { Hishamuddin et al. } \\
\text { (2013), Hsu and Li } \\
\text { (2011), Hu et al. (2013), } \\
\text { Shao and Dong (2012) }\end{array}$ \\
\hline $\begin{array}{l}\overline{\frac{\pi}{2}} \\
\bar{\partial} \\
\overline{0}\end{array}$ & Capacity & & $\begin{array}{l}\text { Azaron et al. } \\
(2008)\end{array}$ & $\begin{array}{l}\text { Schmitt and Singh (2012), } \\
\text { Ivanov et al. (2013, } \\
\text { 2014a) }\end{array}$ & Hsu and Li (2011) \\
\hline ن & Backup suppliers & $\begin{array}{l}\text { Lim et al. } \\
(2010), \text { Li et al. } \\
(2013)\end{array}$ & & $\begin{array}{l}\text { Schmitt and Singh (2012), } \\
\text { Vahdani et al. (2011) }\end{array}$ & $\begin{array}{l}\text { Hou et al. (2010), Shao } \\
\text { and Dong (2012) }\end{array}$ \\
\hline & Fixed costs & $\begin{array}{l}\text { Lim et al. } \\
(2010), \text { Li et al. } \\
(2013)\end{array}$ & $\begin{array}{l}\text { Azaron et al. } \\
\text { (2008), Torabi } \\
\text { et al. (2015) }\end{array}$ & $\begin{array}{l}\text { Ivanov et al. (2013, } \\
\text { 2014a) }\end{array}$ & Hsu and $\mathrm{Li}(2011)$ \\
\hline 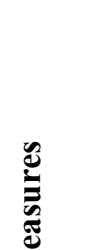 & Variable costs & $\begin{array}{l}\text { Lim et al. } \\
\text { (2010), Li et al. } \\
(2013)\end{array}$ & $\begin{array}{l}\text { Sawik (2013, } \\
\text { 2016), Torabi et } \\
\text { al. (2015) }\end{array}$ & $\begin{array}{l}\text { Carvalho et al. (2012), } \\
\text { Schmitt and Singh (2012), } \\
\text { Vahdani et al. (2011), } \\
\text { Ivanov et al. (2013, } \\
\text { 2014a), Ivanov et al. } \\
\text { (2016a,b), Ivanov (2017) }\end{array}$ & $\begin{array}{l}\text { Hishamuddin et al. } \\
\text { (2013), Hsu and Li } \\
\text { (2011), Hou et al. (2010), } \\
\text { Hu et al. (2013), Iakovou } \\
\text { et al. (2010), Shao and } \\
\text { Dong (2012) }\end{array}$ \\
\hline 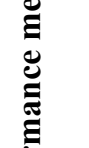 & Disruption costs & Li et al. (2013) & & $\begin{array}{l}\text { Ivanov et al. (2013, } \\
\text { 2014b), Ivanov et al. } \\
(2016 a, b), \text { Ivanov (2017) }\end{array}$ & $\begin{array}{l}\text { Hishamuddin et al. } \\
\text { (2013), Hu et al. (2013), } \\
\text { Iakovou et al. (2010) }\end{array}$ \\
\hline  & Recovery costs & & $\begin{array}{l}\text { Azaron et al. } \\
(2008)\end{array}$ & $\begin{array}{l}\text { Schmitt and Singh (2012), } \\
\text { Vahdani et al. (2011), Raj } \\
\text { et al. (2014) }\end{array}$ & $\begin{array}{l}\text { Hishamuddin et al. } \\
\text { (2013), Hsu and Li } \\
\text { (2011), Hou et al. (2010), } \\
\text { Hu et al. (2013), Iakovou } \\
\text { et al. (2010) }\end{array}$ \\
\hline & $\begin{array}{l}\text { Service level / } \\
\text { profit }\end{array}$ & $\begin{array}{l}\text { Rezapour et al. } \\
\text { (2017) }\end{array}$ & $\begin{array}{l}\text { Sawik (2013, } \\
\text { 2016). }\end{array}$ & $\begin{array}{l}\text { Schmitt and Singh (2012), } \\
\text { Vahdani et al. (2011), } \\
\text { Ivanov et al. (2013, } \\
\text { 2014a) }\end{array}$ & $\begin{array}{l}\text { Hsu and Li (2011), Hu et } \\
\text { al. (2013), Shao and } \\
\text { Dong (2012), Gupta and } \\
\text { Sethi (2015) }\end{array}$ \\
\hline
\end{tabular}


D. Ivanov, A. Dolgui, B. Sokolov, M. Ivanova. Literature review on disruption recovery in the supply chain

The analysed literature considers three basic types of disruptive risks that should be considered by SC managers:

- production

- supply

- transportation disruptions.

Next, recent literature discussed different redundancy strategies (Fig. 2):

- backup suppliers

- backup depots and transportation channels/modes

- inventory and capacity buffers

- capacity expansion.

Reaction to disruptive events can be performed depending on the severity of disruptions in regard to responsiveness:

- parametrical adaptation

- process adaptation

- structural adaptation.

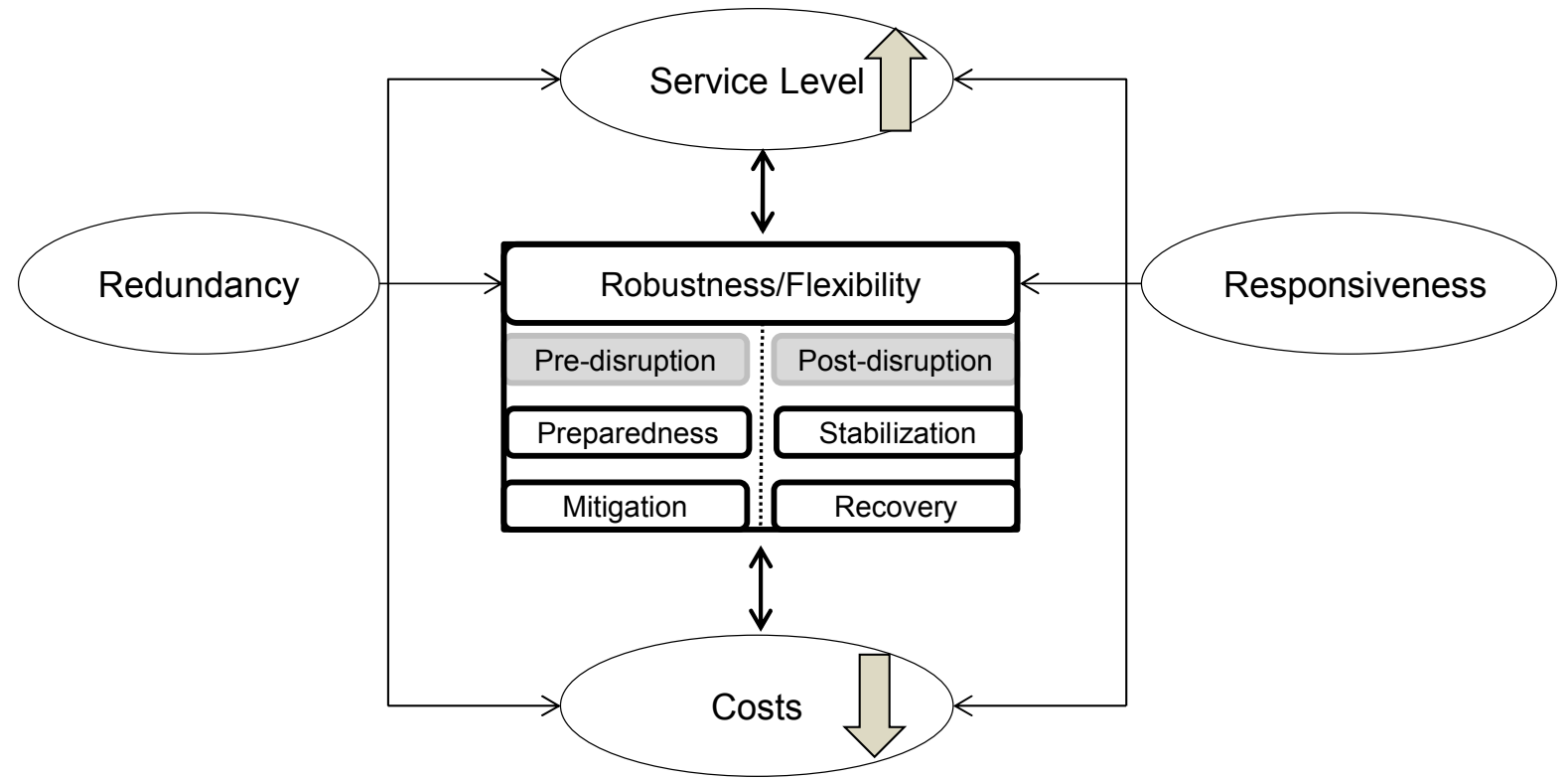

Fig. 2. Proactive and reactive SC disruption risk control strategies

Parametrical adaptation represents the simplest case where stabilization and recovery are possible through tuning of some critical parameters like lead time or inventory. Structure adaptation considers a backup supplier on contingency transportation plans. MIP formulations with facility fortification consider product shift to backup suppliers if primary suppliers are disrupted. Inventory control models also suggest policies for recovery. Simulation techniques consider 'what-if' scenarios which can be used by SC managers in the case of disruption occurrence to quickly estimate the recovery policies and impacts on operational and financial performance.

\subsection{Critical analysis}

MIP models with disruption probabilities can be fairly used in designing resilient SCs subject to costs minimization. Optimization studies empower decision makers to determine the performance impact and resilient SC redesign policies within rigorous analytical solutions. These studies consider a large variety of parameters, variables and objectives, such as SC structures with back-ups, discrete number of periods, demand (distribution) in 
D. Ivanov, A. Dolgui, B. Sokolov, M. Ivanova. Literature review on disruption recovery in the supply chain periods, production capacities in periods, beginning and ending inventory in periods, production quantities in periods, sourcing quantities in periods, shipment quantities in periods, backorder quantities in periods, production, shipment, setup, holding, delay, lost sales, fixed, processing, ordering, backordering costs, disruption duration, in periods, recovery duration, in periods, as well as individual impact on service level, costs, lost sales at the end of planning horizon (Ivanov 2017a).

At the same time, a general shortcoming of existing studies, as pointed out by Cui et al. (2010) and Li et al. (2013) is that the dynamics of SC execution is not considered. Disruptions are mostly considered as static events, without taking into account their duration, stabilization/recovery policies. Similar to MIP, assumptions on the known reliability of suppliers and parametric probabilities make the stochastic programming models generally difficult to handle and implement. In addition, a scenario-based approach exponentially increases the number of variables and constraints in stochastic formulations. For some practical challenges and solutions in this direction, we refer to van Delft and Vial (2004).

Simulation can be considered as a methodology to further enhance the optimization results or it can be even used as simulation-based optimization technique (Gao and Chen 2017). Simulation allows a dynamic consideration of randomness in disruption and recovery policies, real-time analysis, real problem complexity, inventory control policies, dynamic recovery policies, gradual capacity degradation

and recovery, impact of changes in sourcing, transportation and production policies on the ripple effect and operational parameter dynamics in time, multiple performance impact dimensions including financial, service level, and operational performance in time (Ivanov 2017).

The application of fuzzy and robust optimization is related mostly to operational risks (e.g. demand fluctuations) and the tactical planning level with some episodic interfaces to SCD. The same can be stated for control models. In addition, as a general shortcoming of robust optimization, the tendency for quite pessimistic solutions has to be pointed out. In practice, it is hard to assume that managers will accept SCDs with low efficiency and high fixed costs just in anticipation of the worst case.

Summarizing, investment in SC protection can help to avoid many problems with disruptive events. However, it is impossible to avoid disruption completely. Simchi-Levi et al. (2014) underline that focus should be directed at the recovery policies regardless of what caused the disruption. Therefore, adaptation is needed to change SC plans, schedules or inventory policies in order to achieve the desired output performance. In SCs, the adaptation (and more precisely, human-driven coordinated adaptation) is the precondition of stability and robustness (Ivanov and Sokolov 2013). The implications of strategic SCD and tactical SCP on SC performance at the execution and recovery stage can be enhanced by using models based on the dynamics of the execution processes.

\subsection{Managerial implications}

Disruption risks may result in ripple effect and structure dynamics in the SC. It should be noticed that the scope of the rippling and its performance impact depend both on robustness reserves (e.g. redundancies like inventory or capacity buffers) and on the speed and scale of recovery actions (Knemeyer et al. 2009; Hu et al. 2013; Ivanov and Sokolov 2013; Kim and Tomlin 2013; Pettit et al. 2013). In many practical settings, companies need analysis tools to estimate both SC robustness and SC resilience. For SC resilience, the impacts of recovery actions subject to different disruptions and performance indicators need to be estimated (Fig. 3). 


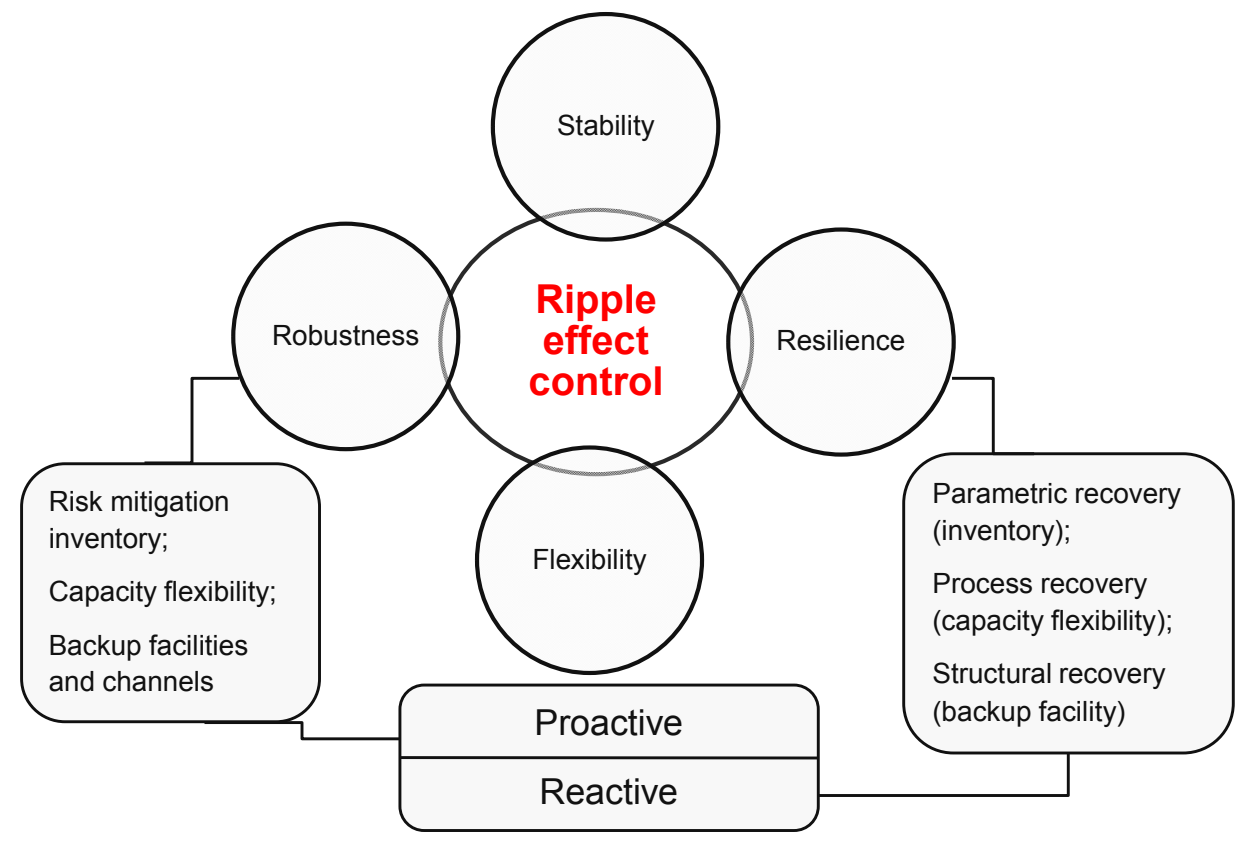

Fig. 3. Ripple effect control framework

Reactive decisions are crucial since the scope of the rippling and its impact on economic performance depends both on robustness reserves (e.g. redundancies like inventory or capacity buffers) and on speed and scale of recovery measures (Hendricks and Singhal 2005; Sheffi and Rice 2005; Tomlin 2006; Bode et al. 2011; Ivanov and Sokolov 2013; Kim and Tomlin 2013). In many practical settings, companies need analysis tools to estimate the impacts of recovery measures subject to different disruptions and performance indicators. Ambulkar et al. (2015) provide the evidence that recovery policies belong to the most important drivers of SC resilience. Such recovery options comprise backup strategies (e.g. backup suppliers, warehouses, depots and transportation channels), inventory and capacity expansion. Contingency plans or backup planning (e.g. alternative suppliers or shipping routes) need to be developed (Knemeyer et al. 2009; Cui et al. 2010; Yang et al. 2012; Benyoucef et al. 2013; Li et al. 2013; Stevenson and Busby 2015). The recovery must happen quickly to expedite stabilization and adaptation in order to ensure SC continuity and avoid long-term impact. In implementing such recovery policies, companies need a tool supported by collaboration and SC visibility solutions for assessing the impact of disruption on the SC as well as the effects from redirecting material flows (Sheffi and Rice 2005; Chopra and Sodhi 2014; Simchi-Levi et al. 2014). The results of the literature can contribute to supporting decisions in these practical problems (Table 3). 
D. Ivanov, A. Dolgui, B. Sokolov, M. Ivanova. Literature review on disruption recovery in the supply chain

Table 3. Matrix of managerial implications

\begin{tabular}{|c|c|c|c|c|c|}
\hline & Sourcing & Production & Distribution & Integrated SCM & \\
\hline Strategic & $\begin{array}{l}\text { Segment suppli- } \\
\text { ers according to } \\
\text { disruption risks; } \\
\text { Optimize inven- } \\
\text { tory management }\end{array}$ & $\begin{array}{l}\text { Segment produc- } \\
\text { tion cites accord- } \\
\text { ing to disruption } \\
\text { risks; } \\
\text { Increase manu- } \\
\text { facturing process } \\
\text { and capacity } \\
\text { flexibility }\end{array}$ & $\begin{array}{l}\text { Increase trans- } \\
\text { portation process } \\
\text { and capacity } \\
\text { flexibility } \\
\text { Optimize inven- } \\
\text { tory management }\end{array}$ & $\begin{array}{l}\text { Create SC visibil- } \\
\text { ity } \\
\text { Prioritize and } \\
\text { allocate resources } \\
\text { according to risk } \\
\text { considerations }\end{array}$ & Risk mitigation \\
\hline Tactical & \multicolumn{4}{|c|}{$\begin{array}{l}\text { Collaborative emergency training in the SC: } \\
\text { Tracking changes, SC monitoring and alerting the executives }\end{array}$} & Preparedness \\
\hline Operative & $\begin{array}{l}\text { Redirect material } \\
\text { flows using } \\
\text { backup suppliers } \\
\text { and inventory }\end{array}$ & $\begin{array}{l}\text { Reallocate re- } \\
\text { sources and } \\
\text { change manufac- } \\
\text { turing plans }\end{array}$ & $\begin{array}{l}\text { Reallocate re- } \\
\text { sources and } \\
\text { change transpor- } \\
\text { tation plans }\end{array}$ & $\begin{array}{l}\text { Reconfigure the } \\
\text { SC by rematch- } \\
\text { ing demand and } \\
\text { supply points }\end{array}$ & $\begin{array}{l}\text { Stabilization } \\
\text { and recovery }\end{array}$ \\
\hline
\end{tabular}

Despite the significant progress and results gained, the literature review undertaken, its analysis and the observations derived from these allow us to identify and define some crucial gaps which may be considered as opportunities for future research.

\section{FUTURE RESEARCH AGENDA}

\subsection{Methodical issues}

\subsubsection{Recovery policies and quantitative methods}

Recent research on SCM considered issues related to the ripple effect from different perspectives. They include SC resilience with pre- and post-disruption views, SC flexibility, business processes, mathematical models and ICT (information and communications technology). However, in the analysed domain of SCD and SCP with disruptions and recovery, quantitative analysis techniques are considered separately from process and ICT points of view.

The efficient application of model-based support for any quantitative analysis implies a clear description of control processes in the case of different deviations and disturbances. Such processes (i.e. control loops) should also include different control objectives and strategies (e.g. recovering planned execution, maintaining plan stability, minimizing future impacts, etc.). In addition, impacts of control actions on economic performance and related costs of control have not so far been sufficiently considered in the literature.

\subsubsection{Problem and model taxonomy}

Unlike the SCM domain, the SC recovery domain has so far only been addressed episodically. That is why further efforts are needed to develop a taxonomy of this research field in regard to problem classification, methodical frameworks, and application recommendations. Such a taxonomy would help to postulate SC disruption management as an independent research domain. In addition, it would provide managers with tangible guidelines of proactive and reactive policies for different business models and SC structures.

\subsubsection{Information and communications technology}


D. Ivanov, A. Dolgui, B. Sokolov, M. Ivanova. Literature review on disruption recovery in the supply chain

From the ICT side, feedback control can be supported by SCEM (supply chain event management) systems and RFID (radio-frequency identification) technology which can be used to effectively communicate these disruptions to the other tiers, and help revise initial processes. A critical issue in this area is detecting the disruptions and their scope in real time. Embedding SC visualization and identification technology is crucial for the successful application of quantitative methods. We regard these shortcomings as an opportunity for research. In particular, the following future research directions can be stated.

\subsection{Performance and resilience measurement in SC design and planning models}

Even if a number of remarkable studies have been published on disruption-related performance measures such as resilience, robustness, stability, and flexibility, there is still a gap between practical needs and research results. Therefore we relate this domain as a future research opportunity. The objective of research in this class is to develop systematic principles for computing different disruption.-related performance measures and embedding them into supply chain performance measurement systems. A crucial role in this domain play the issues of data acquisition. In this regard, Big Data and business intelligence technologies may be very helpful (Ivanov 2017b). Finally, analysis of long-term impacts of control actions and creation of a performance measurement system for the SC dynamics and control domain may be an interesting research avenue.

\subsection{Developing the recovery policies}

From a practical point of view, the research in this domain is to provide managers with new tools in order to support them in decisions on how to

(i) estimate the performance impact of capacity disruptions at the SCD stage;

(ii) quickly estimate the performance impact of real plan disruptions at the execution stage;

(iii) suggest efficient and effective stabilization and recovery measures.

This issue of an integrated analysis of execution policies and the achievement of planned economic performance in a real uncertain and perturbed execution environment is considered. A crucial practical problem is to determine where exactly changes are needed: in the schedule, in the master plan or in the business plan. Such an analysis should incorporate multiple control loops including corresponding business-process models, quantitative models, and ICT for gathering and processing real-time data. Decentralized interests in SC enterprises also have to be included in such analyses.

Different control strategies regarding construction of the optimal recovery programmes can be analysed based on cybernetic principles of critical events, final deviations, free trajectories and interim solutions. For example, an immediate adaptation programme (i.e. immediate recovery and return on the planned execution) and a smooth adaptation programme (i.e. constructing an alternative execution in anticipation of new perturbations) can be compared. In addition, different control objectives may be considered such maintaining planned economic performance, extremizing this performance through control, or maintaining plan stability rather than recovering the planned economic performance.

\subsection{Costs analysis and performance measurement for recovery stage}

In previous research, cost analysis has rarely been included in the SC control models. In this regard, costs of adaptation require a detailed analysis in interconnection with proactive risk mitigation costs. In this case, different trade-offs can be considered, e.g., service level vs costs (Fig. 4). 
Two disruption scenarios I and II

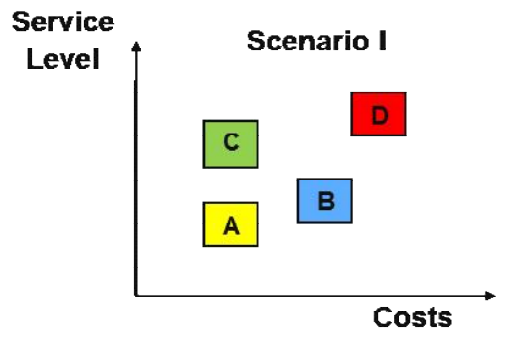

Four combinations of proactive and reactive policies $A, B, C$, and D

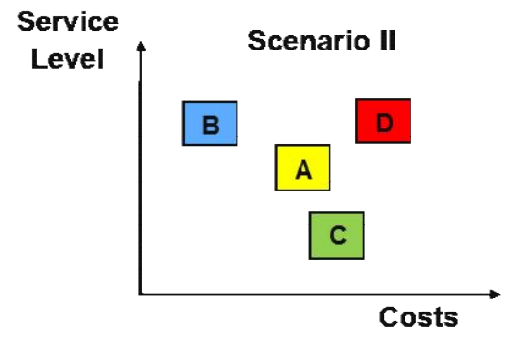

Fig. 4. Trade-off service level vs costs

Consideration can be given to the fact that risk mitigation costs are real but the protection effects and recovery costs can only be anticipated. For scenarios of different scope and severity, these constellation may be different for various combinations of proactive and reactive policies. Cost analysis can also be extended by analysing deviation costs both as operative losses and long-term future impacts of deviation and recovery.

\subsection{Time aspects in disruptions and recovery policies}

Literature on SCD and SCP with disruption considerations mostly considers the recovery policies under the assumption that the disrupted facilities or transportation channels do not return into the SC operation during the planning horizon. There are only a few studies that incorporate SC plan reconfiguration into the performance impact assessment. Therefore more studies are needed that consider temporary absence of some SC elements taking into account the duration of disruptions with the capacity recovery and the costs of this recovery. New methods to compare SC recovery policies with simultaneous performance impact assessment need to be developed. Hybrid optimization-based simulation techniques may potentially make it possible to analyse recovery dynamics with gradual capacity degradation/recovery.

\subsection{Interfaces of resilience and sustainability}

Resilience issues in SCs go far beyond risk management only. The methodical elaborations on the evaluation and understanding of low-frequency/high-impact disruptions are vital for understanding and further development of SCD and control concepts in a broader sense and from a cross-disciplinary perspective. One of the important interfaces is design and management of resilient and sustainable supply chains (Fahimnia and Jabbarzadeh 2016).

In this setting, the development of models and decision support tools can improve decision making on resilient and sustainable supply chains (Brandenburg and Rebs 2015; Giannakis and Papadopoulos 2016). Studies on supply chain sustainability differ across methodologies but they commonly argue that the adoption of sustainable supply chains is maintaining business continuity in order to reduce long-term business risks. Business continuity is at the same time one of the fundamental characteristics of supply chain resilience.

Resilience has a number of intersections with SC sustainability. Since SCs became more and more global, these network structures build a backbone of modern economy and directly influence such sustainability issues as employment rates, natural resource consumption, etc. Important issues of SC sustainability are an assessment of SCD resilience and efficient SC structure reconfiguration in the case of disruptions from the perspectives of environmental, political, and society impacts. 
D. Ivanov, A. Dolgui, B. Sokolov, M. Ivanova. Literature review on disruption recovery in the supply chain

In practice, there are tangible intersections in which sustainability and resilience can influence each other. SC resilience increase is driven by using backup facilities, inventory buffers, eliminating single source suppliers with high risk exposure, and facility fortification. From sustainability point of view, single sourcing, inventory reductions, and labour market stability in regions are important. Multiple complementary objectives and tradeoffs can be investigated in this area.

\section{CONCLUSIONS}

Frameworks for tackling operational and disruption SC risks in light of the bullwhip effect and ripple effects have been extensively studied in literature over the past two decades. Most of them include the following elements:

- mitigating uncertainty at the SCD and SCP stage

- continuous preparedness and risk control

- response and stabilization of process execution in the case of deviations or disruptions

- recovering and minimizing middle-term and long-term impacts of deviations and disruptions.

Numerous empirical frameworks have been developed for analysis of SC risks and recovery measures. In recent years, remarkable advancements have also been achieved in quantitative analysis methods for SCD and SCP under uncertainty and risks. Those methods include mathematical optimization, simulation, inventory management, control and systems science.

The objective of this survey was to reveal application areas of different quantitative methods from SC risk analysis in SCD and SCP. We could observe that the majority of quantitative research pertains to demand and leadtime fluctuations at the operational risks side and structural disruptions at the disruption risks side. Proactive and recovery measures, different redundancies (e.g. inventory, capacity buffers, backup suppliers) and flexibility strategies (e.g. dual or multiple sourcing, product and process flexibility and coordination concepts) are typically considered with a clear domination of the redundancy area.

As limitations of quantitative analysis application to SC disruption control, it should be noticed that main events in the model such as disruption start, full recovery, high inventory increase, system stabilization, product writeoff and the resulting problems with service level are significantly distributed in time. In the simulation model, the impacts of these events on SC efficiency and service level can be estimated according to the final experiment results. In real life, such a retrospective methodology can be applied conditionally to performance impact analysis.

It can also be observed from the analysis that a number of empirically identified important areas of SC risk management and control have attracted little attention in quantitative analysis. We regard this as a future research opportunity. A future research agenda includes issues of integrating operability objectives as new key performance indicators, e.g. resilience, stability, robustness into SCD decisions. Elements of recovery should be considered integrated with proactive models. Such integration requires simultaneous consideration of both the static structural properties of SCD and execution dynamics subject to uncertainty and disruptions. In investigating the dynamic behaviour of the SC, an interesting research avenue would be to apply dynamic systems theory in combination with mathematical programming methods. Finally, organizational behaviour in mitigating and recovering risks is an under-explored area in management science/operations research methods. 
D. Ivanov, A. Dolgui, B. Sokolov, M. Ivanova. Literature review on disruption recovery in the supply chain

\section{Funding}

The research is supported by Russian Science Foundation (Project No. 16-19-00199).

\section{Acknowledgement}

The authors thank two anonymous reviewers for their valuable comments that greatly improved the manuscript.

\section{References}

Acar, Y., S. Kadipasaoglu, S., and P. Schipperijn. (2010). A demand decision support framework for global supply chain modelling: An assessment of the impact of, supply and lead-time uncertainties on performance. International Journal of Production Research 48(11): 3245-3268.

Ahmadi-Javid A., and A. H. Seddighi. (2013). A location-routing problem with disruption risk. Transportation Research Part E: Logistics and Transportation Review 53, 63-82.

Ambulkar, S., J. Blackhurst, and S. Grawe. (2015). Firm's resilience to supply chain disruptions: Scale development and empirical examination. Journal of Operations Management 33(34): 111-122.

Aqlan, F., Lam S. S., 2015. Supply chain risk modelling and mitigation. International Journal of Production Research 53 (18), 5640-5656.

Askin, R.G., Ilaria Baffo, and Mingjun Xia (2014). Multi-commodity warehouse location and distribution planning with inventory consideration. International Journal of Production Research 52(7): 1897-1910.

Azaron, A., K. N. Brown, S. A. Tarim, and M. Modarres. (2008). A multi-objective stochastic programming approach for supply chain design considering risk. International Journal of Production Economics 116(1): $129-138$.

Baghalian, A., S. Rezapour, and R. Z. Farahani. (2013). Robust supply chain network design with service level against disruptions and demand uncertainties: A real-life case. European Journal of Operational Research 227(1): 199-215.

Baron, O., J. Milner, and H. Naseraldin. (2011). Facility location: A robust optimization approach. Production and Operations Management 20(5): 772-785.

Benyoucef, L., X. Xie, and G. A. Tanonkou. (2013). Supply chain network design with unreliable suppliers: A lagrangian relaxation-based approach. International Journal of Production Research 51 (21): 6435-6454.

Blackhurst, J., K. S. Dunn, and C. W. Craighead. (2011). An empirically derived framework of global supply resiliency. Journal of Business Logistics 32(4): 374-391.

Bode, C., S. M. Wagner, K. J. Petersen, and L. M. Ellram. (2011). Understanding responses to supply chain disruptions: Insights from information processing and resource dependence perspectives. Academy of Management Journal 54(4): 833-856.

Bowersox, D.J., D. J. Closs, and M. B. Copper. (2013). Supply Chain Logistics Management. 3rd ed. Boston, MA: McGraw-Hill.

Brandenburg, M., and Rebs, T. (2015). Sustainable supply chain management: A modeling perspec-tive. Annals of Operation Research 229: 213-252. 
D. Ivanov, A. Dolgui, B. Sokolov, M. Ivanova. Literature review on disruption recovery in the supply chain

Carvalho, H., A, P. Barroso, V. H. Machado, S. Azevedo, and V. Cruz-Machado. (2012). Supply chain redesign for resilience using simulation. Computers \& Industrial Engineering 62(1): 329-341.

Chaudhuri, A., B. K. Mohanty, and K. N. Singh. (2013). Supply chain risk assessment during new product development: A group decision making approach using numeric and linguistic data. International Journal of Production Research 51(10): 2790-2804.

Chen, J., A. S. Sohal, and D. I. Prajogo. (2013). Supply chain operational risk mitigation: A collaborative approach. International Journal of Production Research 57(1): 2186-2199.

Chen, Q., X. Li, and Y. Ouyang. (2011). Joint inventory-location problem under the risk of probabilistic facility disruptions. Transportation Research Part B: Methodological, 45(7): 991-1003.

Chen, L., \& Miller-Hooks, E. (2012). Resilience: an indicator of recovery capability in intermodal freight transport. Transportation Science, 46(1), 109-123.

Chopra, S., and M. S. Sodhi. (2014). Reducing the risk of supply chain disruptions. MIT Sloan Management Review 55(3): 73-80.

Chopra, S., and P. Meindl. (2012). Supply Chain Management. Strategy, Planning and Operation. 5th ed. London: Pearson.

Chopra, S., G. Reinhardt, and U. Mohan. (2007). The importance of decoupling recurrent and disruption risks in a supply chain. Naval Research Logistics 54(5): 544-555.

Christopher, M., C. Mena, O. Khan, and O. Yurt. (2011). Approaches to managing global sourcing risk. Supply Chain Management: An International Journal 16(2): 67-81.

Costantino, A., M. Dotoli, M. Falagario, M. P. Fanti, and A, M. Mangini. (2012). A model for supply management of agile manufacturing supply chains. International Journal of Production Economics 135: 451-457.

Craighead, C., J. Blackhurst, M. Rungtusanatham, and R. Handfield. (2007). The severity of supply chain disruptions: Design characteristics and mitigation capabilities. Decision Sciences 38(1): 131-156.

Cui, T., Y. Ouyang, and Z.-J. M. Shen. (2010). Reliable facility location design under the risk of disruptions. Operations Research 58(4-part-1): 998-1011.

Dejonckheere, J., Disney, S.M., Lambrecht, M.R., Towill, D.R., 2003. Measuring and avoiding the bullwhip effect: A control theoretic approach. European Journal of Operational Research 147 (3), 567-590.

Fahimnia B., Jabbarzadeh A. (2016). Marrying supply chain sustainability and resilience: A match made in heaven. Transportation Research Part E: Logistics and Transportation Review, 91, 306-324.

Federgruen, A., and N. Yang. (2011). Procurement strategies with unreliable suppliers. Operations Research 59(4): 1033-1039.

Gao S. and W. Chen (2017) A Partition-based Random Search for Stochastic Constrained Optimization via Simulation, IEEE Transactions on Automatic Control, 62(2): 740-752.

Gedik, R., Medal, H., Rainwater, C.E., Pohl, E.A., Mason, S.J. (2014). Vulnerability Assessment and ReRouting of Freight Trains under Disruptions: A Coal Supply Chain Network Application, Transportation Research Part E: Logistics and Transportation Review, 71, 45-57. 
D. Ivanov, A. Dolgui, B. Sokolov, M. Ivanova. Literature review on disruption recovery in the supply chain

Georgiadis, M.C., P. Tsiakis, P. Longinidis, and M. K. Sofioglou. (2011). Optimal design of supply chain networks under uncertain transient demand variations. Omega 39(3): 254-272.

Giannakis, M., and Papadopoulos, T. (2016) Supply chain sustainability: A risk management ap-proach. International Journal of Production Economics 171(4): 455-470.

Goh, M., J. Y. S. Lim, and F. Meng. (2007). A stochastic model for risk management in global chain networks. European Journal of Operational Research 182(1): 164-173.

Govindan K. (2015). The optimal replenishment policy for time-varying stochastic demand under vendor managed inventory. European Journal of Operational Research 242(2): 402-423.

Govindan, K., Jafarian, A., Azbari, M. E. \& Choi, T. M. (2015). Optimal Bi-Objective Redundancy Allocation for Systems Reliability and Risk Management. IEEE Transactions on Cybernetics. 99, 1-14.

Gunasekaran A., Subramanian H., Rahman S. (2015). Supply chain resilience: role of complexities and strategies. International Journal of Production Research, 53(22), 6809-6819.

Gupta W., He B., Sethi S.P. (2015). Contingent sourcing under supply disruption and competition. International Journal of Production Research, 53(10), 3006-3027.

Gupta, S., Starr, M. K., Farahani, R. Z. and Matinrad, N. (2016), Disaster Management from a POM Perspective: Mapping a New Domain. Production and Operations Management, 25: 1611-1637.

Hallikas, J., I. Karvonen, U. Pulkkinen, V. M. Virolainen, and M. Tuominen. (2004). Risk management processes in supplier networks. International Journal of Production Economics 90(1): 47-58.

Hasani, A., A. Khosrojerdi (2016). Robust global supply chain network design under disruption and uncertainty considering resilience strategies: A parallel memetic algorithm for a real-life case study. Transportation Research Part E: Logistics and Transportation Review, 87, 20-52.

Hendricks, K.B., and V. R. Singhal. (2005). Association between supply chain glitches and operating performance. Management Science 51(5): 695-711.

Hishamuddin, H., R. A. Sarker, and D. Essam. (2013). A recovery model for a two-echelon serial supply chain with consideration of transportation disruption. Computers and Industrial Engineering 64(2): 552-561.

Ho, W., T. Zheng, H. Yildiz \& S. Talluri (2015) Supply chain risk management: a literature review. International Journal of Production Research, 53(16), 5031-5069.

Hora, M., and R. D. Klassen. (2013). Learning from others' misfortune: Factors influencing knowledge acquisition to reduce operational risk. Journal of Operations Management 31, 52-61.

Hou, J., A. Z. Zeng, and L. Zhao. (2010). Coordination with a backup supplier through buy-back contract under supply disruption. Transportation Research Part E: Logistics and Transportation Review 46(6): 881-895.

Hsu, C.I., and H. C. Li. (2011). Reliability evaluation and adjustment of supply chain network design with demand fluctuations. International Journal of Production Economics 132(1): 131-145.

Hu, X., H. Gurnani, and L. Wang. (2013). Managing risk of supply disruptions: Incentives for capacity restoration. Production and Operations Management 22(1): 137-150. 
D. Ivanov, A. Dolgui, B. Sokolov, M. Ivanova. Literature review on disruption recovery in the supply chain

Iakovou, E., D. Vlachos, and A. Xanthopoulos. (2010). A stochastic inventory management model for a dual sourcing supply chain with disruptions. International Journal of Systems Science 41(3): 315-324.

Ivanov D. (2017a) Simulation-based ripple effect modelling in the supply chain. International Journal of Production Research, 55(7), 1083-1101.

Ivanov D. (2017b) Simulation-based single vs dual sourcing analysis in the supply chain with consideration of capacity disruptions, Big Data and demand patterns. International Journal of Integrated Supply Management, 11(1), 24-43.

Ivanov D., A. Tsipoulanidis, and J. Schönberger. (2017). Global Supply Chain and Operations Management, 1st ed. London: Springer International.

Ivanov D., B. Sokolov, A. Pavlov, A. Dolgui, and D. Pavlov. (2016a). Disruption-driven supply chain (re)planning and performance impact assessment with consideration of pro-active and recovery policies. Transportation Research: Part E 90: 7-24.

Ivanov, D., and B. Sokolov. (2013). Control and system-theoretic identification of the supply chain dynamics domain for planning, analysis, and adaptation of performance under uncertainty. European Journal of Operational Research 224(2): 313-323.

Ivanov, D., B. Sokolov, A. Dolgui, I. Solovyeva, and F. Jie. (2016b). Dynamic recovery policies for time-critical supply chains under conditions of ripple effect. International Journal of Production Research, 54(23), 33973413.

Ivanov, D., B. Sokolov, and A. Dolgui. (2014a). The ripple effect in supply chains: Trade-off 'efficiencyflexibility-resilience' -in disruption management. International Journal of Production Research 52(7): 2154 2172 .

Ivanov, D., B. Sokolov, and A. Pavlov. (2013). Dual problem formulation and its application to optimal redesign of an integrated production-distribution network with structure dynamics and ripple effect considerations. International Journal of Production Research 51(18): 5386-5403.

Ivanov, D., B. Sokolov, and A. Pavlov. (2014b). Optimal distribution (re)planning in a centralized multi-stage network under conditions of ripple effect and structure dynamics. European Journal of Operational Research 237(2): 758-770.

Ivanov, D., Dolgui, A., Sokolov, B., Ivanova M. (2016c). Disruptions in supply chains and recovery policies: state-of-the art review. IFAC-PapersOnLine 49(12), 8th IFAC Conference on Manufacturing Modelling, Management and Control (MIM 2016), Edited by Alexandre Dolgui, Robert Grubbström, Dmitry Ivanov and Farouk Yalaoui, pp. 1436-1441.

Kamalahmadi, M. and Parast, M.M. (2016). A review of the literature on the principles of enterprise and supply chain resilience: Major findings and directions for future research". International Journal of Production Economics, 171(1), 116-133.

Khalili SM., F. Jolai \& S.A. Torabi (2017). Integrated production-distribution planning in two-echelon systems: a resilience view. International Journal of Production Research, 55(4), 1040-1064. 
D. Ivanov, A. Dolgui, B. Sokolov, M. Ivanova. Literature review on disruption recovery in the supply chain

Kim, S.H., and B. Tomlin. (2013). Guilt by association: Strategic failure prevention and recovery capacity investments. Management Science 59(7): 1631-1649.

Kleindorfer, P.R., and G. H. Saad. (2005). Managing disruption risks in supply chains. Production and Operations Management 14(1): 53-68.

Klibi, W., A. Martel, and A. Guitouni. (2010). The design of robust value-creating supply chain networks: A critical review. European Journal of Operational Research 203(2): 283-293.

Klibi, W., and A. Martel. (2012). Modeling approaches for the design of resilient supply networks under disruptions. International Journal of Production Economics 135(2): 882-898.

Knemeyer, A.M., W. Zinn, and C. Eroglu. (2009). Proactive planning for catastrophic events in supply chains. Journal of Operations Management 27(2): 141-153.

Kouvelis, P., and J. Li. (2012). Contingency strategies in managing supply systems with uncertain lead-times. Production and Operations Management 21(1): 161-176.

Kumar S.K., and M. K. Tiwari. (2013). Supply chain system design integrated with risk pooling. Computers \& Industrial Engineering 64, 580-588.

Lewis, B.M, A. L. Erera, M. A. Nowak, and C. C. White III. (2013). Managing inventory in global supply chains facing port-of-entry disruption risks. Transportation Science 47(2): 162-180.

Li, Q., B. Zeng, and A. Savachkin. (2013a). Reliable facility location design under disruptions. Computers \& Operations Research 40(4): 901-909.

Lim, M., M. S. Daskin, A. Bassamboo, and S. Chopra. (2010). A facility reliability problem: Formulation, properties and algorithm. Naval Research Logistics 57(1): 58-70.

Lim, M.K., A. Bassamboo, S. Chopra, and M. S. Daskin. (2013). Facility location decisions with random disruptions and imperfect estimation. Manufacturing and Service Operations Management 15(2): 239-249.

Lin, Y.K., Huang, C.F., Liao Y.-C. \& Yeh, C.T. (2017). System reliability for a multistate intermodal logistics network with time windows. International Journal of Production Research, in press.

Manzini, R., and D. Bindi. (2009). Strategic design and operational management optimization of a multistage physical distribution system. Transportation Research Part E: Logistics and Transportation Review 45(6): 915-936.

Martel A., Klibi W. (2016). Designing Value-Creating Supply Chain Networks. Springer.

Meisel, F., and C. Bierwirth. (2014). The design of make-to-order supply networks under uncertainties using simulation and optimization. International Journal of Production Research 52(22): 6590-6607.

Melo, M.T., S. Nickel, and F. Saldanha-da-Gama. (2009). Facility location and supply chain management - A review. European Journal of Operational Research 196(2): 401-412.

Mizgier K. J. (2017) Global sensitivity analysis and aggregation of risk in multi-product supply chain networks, International Journal of Production Research, 55(1), 130-144.

Nair, A. and Vidal, J. M. 2011. Supply network topology and robustness against disruptions: an investigation using multiagent model. International Journal of Production Research, 49(5), 1391-1404. 
D. Ivanov, A. Dolgui, B. Sokolov, M. Ivanova. Literature review on disruption recovery in the supply chain

Nair A., Jayaram J., Das A. (2015). Strategic purchasing participation, supplier selection, supplier evaluation and purchasing performance. International Journal of Production Research, 53(20), 6263-6278.

Ouyang, Y., and X. Li. (2010). The bullwhip effect in supply chain networks. European Journal of Operational Research 201(3): 799-810.

Pan, F., and R. Nagi. (2013). Multi-echelon supply chain network design in agile manufacturing. Omega 41, 969-983.

Paul, S.K., R. Sarker, and D. Essam. (2014). Real time disruption management for a two-stage batch productioninventory system with reliability considerations. European Journal of Operational Research 237, 113-128.

Peng, P., L. V. Snyder, A. Lim, and Z. Liu. (2011). Reliable logistics networks design with facility disruptions. Transportation Research Part B: Methodological 45(8): 1190-1211.

Pettit, T.J., K. L. Croxton, and J. Fiksel. (2013). Ensuring supply chain resilience: Development and implementation of an assessment tool. Journal of Business Logistics 34(1): 46-76.

Qi, L. (2013). A continuous-review inventory model with random disruptions at the primary supplier. European Journal of Operational Research 225(1): 59-74.

Rafiei, M., M. Mohammadi, and S. Torabi. (2013). Reliable multi period multi product supply chain design with facility disruption. Decision Science Letters 2(2): 81-94.

Ravindran, A., R. U. Bilsel, V. Wadhwa, and T. Yang. 2010. Risk adjusted multicriteria supplier selection models with applications. International Journal of Production Research 48(2): 405-424.

Raj, R.; Wang, J; Nayak, A; Tiwari, WK; Han, B; Liu, C; Zhang, WJ (2014). Measuring the Resilience of Supply Chain Systems Using a Survival Model. IEEE Systems Journal, 9(2), 377-381.

Rezapour, S., Farahani, R., Pourakbar, M. (2017) Resilient supply chain network design under competition: a case study. European Journal of Operational Research. 259(3), 1017-1035.

Ritchie, B., and C. Brindley. (2007). Supply chain risk management and performance: A guiding framework for future development. International Journal of Operations and Production Management 27(3): 303-322.

Sadjady, H., and H. Davoudpour, H. (2012). Two-echelon, multi-commodity supply chain network design with mode selection, lead-times and inventory costs. Computers \& Operations Research 39, 1345-1354.

Santoso, T., S. Ahmed, G. Goetschalckx, and A. Shapiro. (2005). A stochastic programming approach for supply chain network design under uncertainty. European Journal of Operational Research 167, 96-115.

Sawik T. (2016). On the risk-averse optimization of service level in a supply chain under disruption risks. International Journal of Production Research, 54(1), 98-113.

Sawik, T. (2013). Integrated selection of suppliers and scheduling of customer orders in the presence of supply chain disruption risks. International Journal of Production Research 51(23-24): 7006-7022.

Schmidt, W., and D. Simchi-Levi. (2013). Nissan Motor Company Ltd.: Building Operational Resiliency. MIT Sloan Management pp.1-12

Schmitt, A.J., and M. Singh (2012). A quantitative analysis of disruption risk in a multi-echelon supply chain. International Journal of Production Economics 139(1): 23-32. 
D. Ivanov, A. Dolgui, B. Sokolov, M. Ivanova. Literature review on disruption recovery in the supply chain

Shao, X.F., and M. Dong. (2012). Supply disruption and reactive strategies in an assemble-to-order supply chain with time-sensitive demand. IEEE Transactions on Engineering Management 59(2): 201-212.

Sheffi, Y., and J. B. Rice. (2005). A supply chain view of the resilient enterprise. MIT Sloan Management Review 47(1): 41-48.

Simangunsong, E., L. C. Hendry, and M. Stevenson. (2012). Supply-chain uncertainty: A review and theoretical foundation for future research. International Journal of Production Research 50(16): 4493-4523.

Simchi-Levi, D., W. Schmidt, and Y. Wei. (2014). From superstorms to factory fires: Managing unpredictable supply chain disruptions. Havard Business Review February.

Singh, A.R., P. K. Mishra, R. Jain, and M. K. Khurana. (2012). Design of global supply chain network with operational risks. International Journal of Advanced Manufacturing Technology 60(1-4): 273-290.

Snyder, L V., Zümbül A., Peng P., Ying R., A. J. Schmitt, and B. Sinsoysal (2016). OR/MS Models for Supply Chain Disruptions: A Review. IIE Transactions, 48(2), 89-109.

Snyder, L.V., and M. S. Daskin. (2005). Reliability models for facility location: The expected failure cost case. Transportation Science 39: 400-416.

Sodhi, M.S., and S. Lee. (2007). An analysis of sources of risk in the consumer electronics industry. Journal of the Operational Research Society 58(11): 1430-1439.

Sodhi, M.S., B. G.Son, and C. Tang. (2012). Researchers' perspectives on supply chain risk management. Production and Operations Management 21(1): 1-13.

Sokolov, B., Ivanov, D., Dolgui A., Pavlov A. (2016). Structural analysis of the ripple effect in the supply chain. International Journal of Production Research, 54(1), 152-169.

Sourirajan, K., L. Ozsen, and R. Uzsoy (2009). A genetic algorithm for a single product network design model with lead time and safety stock considerations. European Journal of Operational Research 197: 599-608.

Spiegler, V., Naim, M. and Wikner, J. (2012). A control engineering approach to the assessment of supply chain resilience. International Journal of Production Research 50:6162-6187.

Spiegler, V.L.M. and Naim, M. (2017) Investigating sustained oscillations in nonlinear production and inventory control models. European Journal of Operational Research, in press.

Spiegler, V.L.M., A.T. Potter, M.M. Naim \& D.R. Towill (2016). The value of nonlinear control theory in investigating the underlying dynamics and resilience of a grocery supply chain. International Journal of Production Research, 54(1), 265-286.

Stevenson M., and J. Busby. (2015). An exploratory analysis of counterfeiting strategies", International Journal of Operations \& Production Management 35(1): 110-144.

Tang, C.S., 2006. Perspectives in supply chain risk management. International Journal of Production Economics 2006; 103: 451-488.

Tang, S.Y., H. Gurnani, and D. Gupta. (2014). Managing disruptions with endogenous supply reliability. Production and Operations Management 23(7): 1198-1211. 
D. Ivanov, A. Dolgui, B. Sokolov, M. Ivanova. Literature review on disruption recovery in the supply chain

Tomlin, B. (2006). On the value of mitigation and contingency strategies for managing supply chain disruption risks. Management Science 52: 639-657.

Torabi S.A., Baghersad, M., Mansouri, S.A. (2015). Resilient supplier selection and order allocation under operational and disruption risks. Transportation Research Part E: Logistics and Transportation Review, 79, 2248.

Tsai W.C. (2016) A dynamic sourcing strategy considering supply disruption risks. International Journal of Production Research, 54(7), 2170-2184.

Tsiakis, P., N. Shah, and C. C. Pantelides. (2001). Design of multi-echelon supply chain networks under demand uncertainty. Industrial \& Engineering Chemistry Research 40: 3585-3604.

Tukamuhabwa, B.R., M. Stevenson, J Busby \& Marta Zorzini (2015). Supply chain resilience: definition, review and theoretical foundations for further study. International Journal of Production Research, 53(18), 55925623.

Unnikrishnan, A., and M. Figliozzi. (2011). Online freight network assignment model with transportation disruptions and recourse. Transportation research record. Journal of the Transportation Research Board 2224(1): $17-25$.

Vahdani, B., M. Zandieh, and V. Roshanaei. (2011). A hybrid multi-stage predictive model for supply chain network collapse recovery analysis: A practical framework for effective supply chain network continuity management. International Journal of Production Research 49(7): 2035-2060.

van Delft, C., and J.-P. Vial. (2004). A practical implementation of stochastic programming: An application to the evaluation of option contracts in supply chains. Automatica 40: 743-756.

Wilson, M.C. (2007). The impact of transportation disruptions on supply chain performance. Transportation Research Part E: Logistics and Transportation Review 43: 295-320.

Wu, T., J. Blackhurst, and P. O’Grady. (2007). Methodology for supply chain disruption analysis. International Journal of Production Research 45(7): 1665-1682.

Xia, Y., M.-H. Yang, B. Golany, S. M. Gilbert, and G. Yu. (2004). Real-time disruption management in a twostage production and inventory system. IIE Transactions 36(2): 111-125.

Xiao, T., \& G. Yu. (2006). Supply chain disruption management and evolutionarily stable strategies of retailers in the quantity-setting duopoly situation with homogeneous goods. European Journal of Operational Research 173(2): 648-668.

Xu, K., Y. Dong, and Y. Xia. (2015). 'Too little' or 'too late': The timing of supply chain demand collaboration. European Journal of Operational Research 241(2): 370-380.

Xu, M., X. Wang, and L. Zhao. (2014). Predicted supply chain resilience based on structural evolution against random supply disruptions. International Journal of Systems Science: Operations \& Logistics 1(2): 105-117.

Yang, Z., G. Aydin, V. Babich, and D. R. Beil. (2012). Using a dual-sourcing option in the presence of asymmetric information about supplier reliability: Competition vs diversification. Manufacturing and Service Operations Management 14(2): 202-217. 
D. Ivanov, A. Dolgui, B. Sokolov, M. Ivanova. Literature review on disruption recovery in the supply chain

Yu, G., F. Li \& Y. Yang (2017). Robust supply chain networks design and ambiguous risk preferences. International Journal of Production Research, 55(4), 1168-1182.

Zsidisin, G., L. Ellram, J, Carter, and J. Cavinato. (2004). An analysis of supply risk assessment techniques. International Journal of Physical Distribution and Logistics Management 34(5): 397-413. 